\title{
The Application of EPON Communication Technology in Intelligent Substation Automation Equipment
}

\author{
Ma Wei ${ }^{1}$, Zhang Yuhui ${ }^{1}$, Xia Zongze ${ }^{1}$, Si Yadong ${ }^{2}$, Zhang Hong ${ }^{3}$, Zhu Yuanda ${ }^{4}$, \\ Wang $\mathrm{Wei}^{4}$, Xu Minghu ${ }^{4}$ \\ ${ }^{1}$ Liaoyang Power Supply Company, Liaoning Electric Power Company Limited, State Grid, China, \\ ${ }^{2}$ Chaoyang Power Supply Company, Liaoning Electric Power Company Limited, State Grid, China, \\ ${ }^{3}$ Jinzhou Power Supply Company, Liaoning Electric Power Company Limited, State Grid, China, \\ ${ }^{4}$ Liaoning Techniques Training Center, State Grid, China, \\ fushunpowersupply@163.com
}

Keywords: intelligent substation; automation equipment; EPON; communication technology

\begin{abstract}
Based on the development and application of the first $220 \mathrm{kV}$ smart substation at Liaoyang Power Supply Company of State Grid Corporation of China and substation automation abroad, this paper expatiates the necessity of intelligent substation equipment and the composition and characteristics of the smart devices from the view of practical engineering application. It discusses the integrated thinking of intelligent substation automation equipment from the view of system design. In the combination with the principle of communication technology, dynamic bandwidth allocation mechanism and the requirement of intelligent substation automation equipment technology of communication support, it applies EPON communication technology to intelligent substation layer networking process and realizes the technique project of automation equipment control function.
\end{abstract}

\section{Introduction}

Smart substation is the important foundation and support of the smart grid, one of its core technologies is network communications technology. At the present stage, Domestic intelligent substation mainly adopts industrial Ethernet switch to make process layer system of communication network system design[1]. Relatively speaking, the process level industrial switch is more expensive than ordinary industrial switches. According to research, the cost of the industrial switches is not cheaper than the whole protection and control equipment of the substation. The relay protection and control equipment of the intelligent substation automation system belongs to the way of "Distributed data acquisition, Centralized functional processing" which uses sampled value data of SV that come from the process layer network scattered collection combiner of the intelligent substation to conduct protection function operation. Finally, it is tripped by the intelligent terminal equipment. Because of its good anti-jamming, fiber is ideally suited for transferring intelligent substation information[2, 3]. The communications between terminal equipment and monitoring systems will be come true only by a OLT, a splitter and some ONU in the whole communication system if EPON can be used to make process layer network. The study of EPON has realistic significance, if it can satisfy the need of real-time and reliability of smart substation and be cheaper than others.

EPON (Ethernet Passive Optical Network) is a type of optical fiber access network technology, which is widely used in telecommunication and internet cafes. It has been initially applied to the distribution automation of power systems and use electricity automation.

\section{The characteristics of the substation automation and the composition of smart devices}

The development process of second production of national substation is composed of protect, measuring, control and communication. With the development of technology and the requirement of 
electric power system automation, substation automation begins from tele control and automation to communication. The early work is only to collect data of part of the state and analog, what's more, it can monitor substation. With the maturity and application of dispatching automation and microcomputer protection, substation automation and unattended mode become to a new problem that need to solve. There are two system structures exist in the development of substation automation which is distributed method and centralized method. Because of the historical reasons of the management method of electric power system and the development of secondary products, most systems are always "knock together" according to functions, instead of according to the need of engineering and the right guiding ideology, so that result in the problem that the descent of performance and arise many unsolvable problems $[4,5]$.

From the developing trend of the distribution, openness and the whole system, it is more superior that using distributed measurement and control, protect, automatic device and computer LAN. The substation automation which adopts distributed and open network topology and computer LAN technology, its field unit can run independently without the system. The system cannot be influenced by the breakdown of single appliance, so as to achieve the objective that "distributed arrangement, centralized management", in addition, it strengthen the reliability and scalability of the system. This kind of structure model is more and more accepted by electric power system in our country, whose main characteristic is to make the most of software and hardware resource, and use communication network instead of cable, which avoid overlapping investment of equipment.

Figure 1 marked the three levels within the substation and the data exchange between them. Starting from the point of view that including substation electricity transmission, allocated for testing and other control and management, we can find that substation is made up of bus, transformer, line, capacitor and some other basic components. A basic element provides data to the secondary system through one or more intervals, then receiving the control commands from the secondary system. According to the characteristics of each basic device itself and detection and control requirement, in accordance with the basic element internal data collection fault detection and isolation by the principle to solve the element itself, intelligent electronic devices(IED) is the thing to design each kind of basic components corresponding to a hardware structure.

The figure tells us that the data can be exchanged between device layer and bay level is not too much, which mainly sent I/O signal from device layer to bay level and sent control signal from bay level to device layer.

There are much data exchanged between bay level and management of substation. On the one hand, the information which is collected by smart device of bay level need upload to local monitoring system and send to distant control center through communication processor. It not only has too much data, but also has high real-time. On the other hand, the system clock control and adjust the command and the setting commands of operational parameter of the management of substation also need be sent to smart devices.

Data exchange also exist among the smart devices of bay level which is not too much and has low requirement for real-time. As most of the protective devices are independent, thus it has little relationship with the other devices on data exchange. The other smart devices also have some data exchange.

Based on the situation above, when design substation automation system we consider to adopt distributed configuration in bay level. If condition permits, the devices of bay level can be installed on the switchgear. All kinds of devices of bay level are independent, which only interconnecting through internal communication network and communicating with devices of substation quickly. 


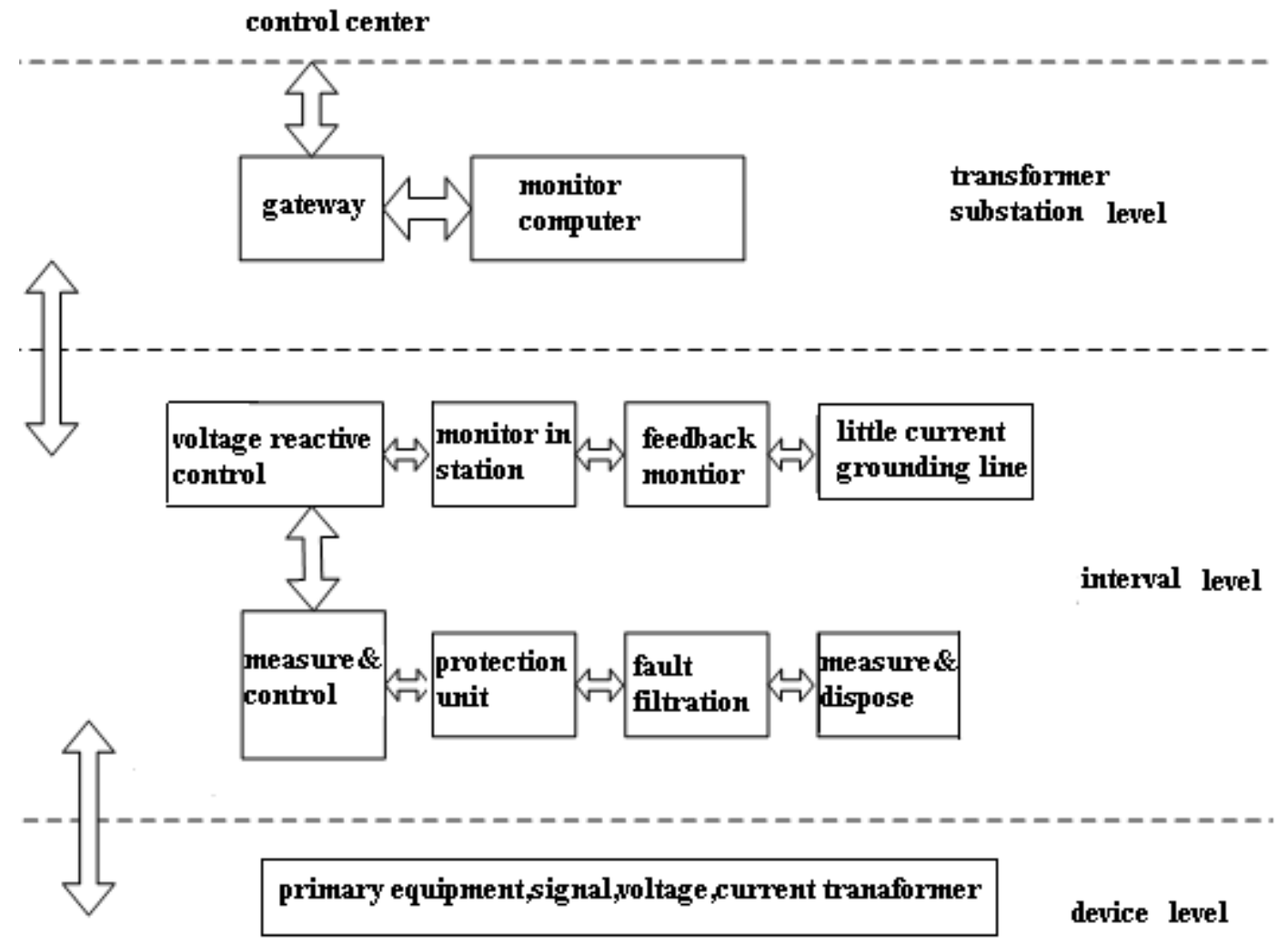

Fig.1 The three levels within the substation and the data exchange between them

\section{LAN communication}

(1) haracteristic of communication service

EPON technology regards optical fiber as the carrier of information transmission network. Its link layer adopts Ethernet protocol which is consistent with smart substation. It's very suitable for application of intelligent substation communication system.

The relay protection and control equipment of the intelligent substation automation system belongs to the way of "Distributed data acquisition, Centralized functional processing" which uses sampled value data of SV that come from the process layer network scattered collection combiner of the intelligent substation to conduct protection function operation. Finally, it is tripped by the intelligent terminal equipment. Because of its good anti-jamming, fiber is ideally suited for transferring intelligent substation information. The communications between terminal equipment and monitoring systems will be come true only by a OLT, a splitter and some ONU in the whole communication system if EPON can be used to make process layer network. The study of EPON is of realistic significance if it can satisfy the need of real-time and reliability of smart substation and be cheaper than others.

(2) Key communication indicators

1) Network traffic

Usually less monitoring data can be transferred from the control layer of intelligent substation, $100 \mathrm{M}$ Ethernet can satisfy network flow completely. While the real-time demands higher CHOOSE message and sampling value message to generate more network traffic. When designing the actual intelligent substation network, we need forecast the data traffic of inside-plant network traffic CHOOSE message and sampling value message to design their networking pattern and network partition.

2) Network bandwidth

Network bandwidth is to point to in a fixed period of time (usually 1 second), the network can pass the biggest bits of data. Like the width of the road, the wider it is, the more cars can pass. The 
wider network bandwidth is, the more data message can get through network. Therefore, bandwidth is to measure technical indicators of network data transmission ability, whose unit is bit/s. Now, the Ethernet we often use is $100 \mathrm{Mbit} / \mathrm{s}$.

3) Network delay

Network delay means data message that costs time from sending computer to receiving computer. The main factors influencing the network delay in Ethernet is a hop routing (Because every switch routing forwarding needs processing time, the more the routing hop, the more network delay is) and network flow(The more network flow, the longer switches and routers queuing time is .Network delay is longer too).

4)Sampling value dispersion

A key indicator of sampling value sending from a smart substation process layer consolidator reflects the homogeneity that sending from sampling value. Normal work combiner needs to have a basic constant sampling value sending interval.80 points sampling of merger generally requires 250us sending interval.

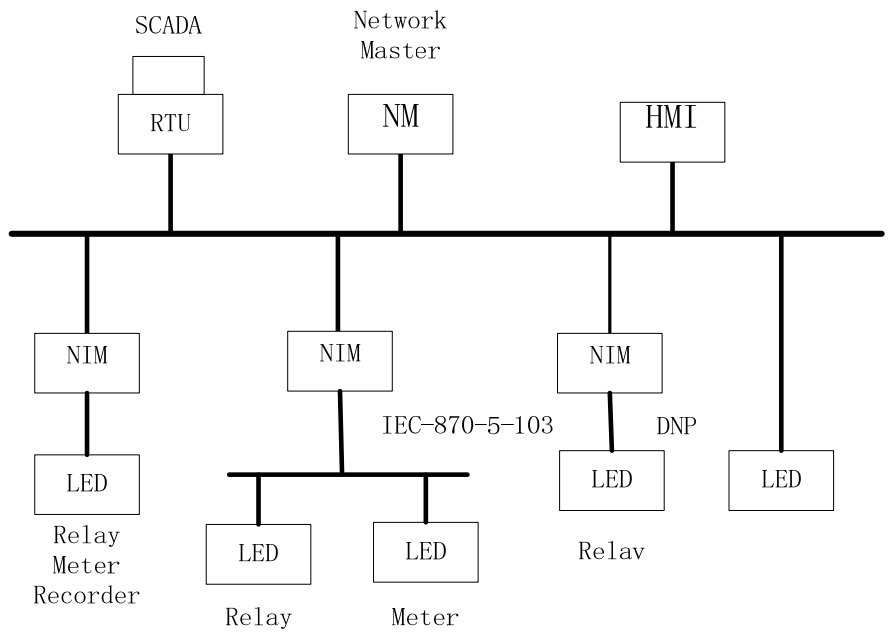

Fig. 2 the communications structure

5)GOOSE transmission delay

GOOSE is a peculiar fast information transmission mechanism of smart substation. Especially it requires a higher transmission performance requirement when getting through GOOSE to finish the important operations of al atresia and protective tripping.

Figure 2 shows the communications structure of substation automation system that widely used in the United States and some European countries. Traditional substation automation products suppliers expand their RTU communication ability, which have multiple serial communication mouth reinforcement RTU to receive various forms of intelligent substation equipment (IED), including measuring meter, relay protection and fault recording equipment. Modern intelligent substation equipment through local area network (LAN) established a large substation control system. Ethernet is used for transformer substation LAN because of its superior performance. Within the substation IED products of different manufacturers can pass code converter (network interface modules NIM) are connected, and part of IED product can be hung directly network running. NIM can be linked together with the bottom of the IED by cheap BS485. Specifications use standard IEC870-5-103 substation relay protection within specifications.IEC870-5-103 specifications have been adopted widely in Europe and other countries which have been affected by the IEC, our country also bring the state grid corporation statute as supporting standard code within the substation.

\section{Summary}

EPON passive features make it beyond the active optical network in terms of stability, whose advantages of low power consumption solve the current intelligent substation heat dissipation of the 
problems of active optical fiber network switch. The application of the passive components such as beam splitter is not only make the network more flexible and convenient, but also simple topology makes maintenance more efficient. Through the reasonable process layer network, it can give full play to the EPON downlink speed, multicast line speed advantage. The application value of EPON is not only in the field of distribution network automation, but also in the process of intelligent substation layer network that has a high application value. The practical experience of the development of substation device and the corresponding composed substation automation system above discuss the understanding and advice of integration and development of intelligent substation automation equipment. Some of the recommendations and design target are still in the stage, but we believe that the rapid development of modern computer technology and network technology will be to achieve the above goals.

\section{References}

[1] IEEE 802.3ah Ethernet in the First Mile Task Force EB/OL, 2001

[2] Sun Xiaoxia. The application of EPON and industrial Ethernet technology in the field of distribution network. 2008

[3] Wei Yong. The practical research of EPON of the process level of intelligent substation. Electrical technology, 2011

[4] Wei Yong. Application analysis on EPON technology applied in communication system of smart substation. International Conference on Information Science and Engineering Application, 2011

[5] Zhihai Liu, Qingliang Zeng, Youfeng Zhu. Barcode technology and programming. Tsinghua University Press, 2009 